\title{
Attitudes of older adults toward shooter video games: An initial study to select an acceptable game for training visual processing
}

\author{
Sandra M. McKay PhD \\ Centre for Studies in Aging, Sunnybrook Health Sciences Centre, \\ Toronto, Ontario M4N 3M5, Canada
}

\author{
Brian E. Maki PhD, PEng \\ Centre for Studies in Aging, Sunnybrook Health Sciences Centre; \\ Institute of Medical Science, Institute of Biomaterials and Biomedi- \\ cal Engineering, Department of Surgery, University of Toronto; \\ Toronto Rehabilitation Institute, Ontario, Canada \\ E: brian.maki@sri.utoronto.ca
}

\begin{abstract}
S.M. McKay, B.E. Maki. Attitudes of older adults toward shooter video games: An initial study to select an acceptable game for training visual processing. Gerontechnology 2010; 9(1):5-17; doi:10.4017/gt.2010.09.01.001.00 A computer-based 'Useful Field of View' (UFOV) training program has been shown to be effective in improving visual processing in older adults. Studies of young adults have shown that playing video games can have similar benefits; however, these studies involved realistic and violent 'first-person shooter' (FPS) games. The willingness of older adults to play such games has not been established. Objectives To determine the degree to which older adults would accept playing a realistic, violent FPS-game, compared to video games not involving realistic depiction of violence. Methods Sixteen older adults (ages 64-77) viewed and rated video-clip demonstrations of the UFOV program and three video-game genres (realistic-FPS, cartoon-FPS, fixed-shooter), and were then given an opportunity to try them out (30 minutes per game) and rate various features. Results The results supported a hypothesis that the participants would be less willing to play the realistic-FPS game in comparison to the less violent alternatives $\left(p^{\prime} s<0.02\right)$. After viewing the video-clip demonstrations, 10 of 16 participants indicated they would be unwilling to try out the realistic-FPS game. Of the six who were willing, three did not enjoy the experience and were not interested in playing again. In contrast, all 12 subjects who were willing to try the cartoon-FPS game reported that they enjoyed it and would be willing to play again. A high proportion also tried and enjoyed the UFOV training (15/16) and the fixed-shooter game (12/15). Discussion A realistic, violent FPS video game is unlikely to be an appropriate choice for older adults. CartoonFPS and fixed-shooter games are more viable options. Although most subjects also enjoyed UFOV training, a video-game approach has a number of potential advantages (for instance, 'addictive' properties, low cost, self-administration at home). We therefore conclude that non-violent cartoon-FPS and fixed-shooter video games warrant further investigation as an alternative to the UFOV program for training improved visual processing in seniors.
\end{abstract}

Keywords: aging, attention, useful field of view, video games, visual training

An impaired ability to rapidly process visual information is common in many older adults $^{1,2}$, and can limit mobility and activities of daily living ${ }^{3,4}$. Moreover, an impaired ability to monitor one's surroundings during activities such as driving can have cata- strophic consequences. Studies have, in fact, shown strong links between impaired ability to rapidly extract information from the peripheral visual field and car-accident risk ${ }^{5,6}$. It is also likely that impaired ability to monitor one's surroundings may increase risk of 
falling. This could arise as a consequence of reduced awareness of hazards that may increase the risk of slipping or tripping, but could also occur as a result of an impaired ability to execute balance-recovery reactions involving rapid compensatory stepping or reaching movements ${ }^{-10}$. For such reactions to be effective in re-stabilizing the body, the hand must be directed very rapidly toward an appropriate object that can be grasped or touched for support, while stepping reactions must be directed so as to avoid obstacles and to land the foot at an appropriate landing site si-10. $^{7}$.

There is now substantial evidence that agerelated visual-processing deficits can be countered via suitably-designed training programs. Specifically, it has been shown that the ability of older adults to rapidly process visual information can be improved by means of a computer-based program that, in effect, increases the 'useful field of view' (UFOV). The UFOV training involves identifying targets that are displayed on a computer screen for very brief intervals (for instance, 17-500 ms) under increasingly challenging conditions (i.e. shorter target display times, more peripheral locations, addition of visual distracters). A series of studies have shown that a moderate degree of UFOV training (10 one-hour sessions) can lead to a persistent $\left(\geq_{11-13}\right.$ vear) increase in visual-processing speed $^{11-13}$, and that the training benefits can transfer to safer driving ${ }^{14}$ and more rapid execution of instrumental activities of daily living ${ }^{15}$.

While UFOV training is clearly an effective intervention to improve visual processing, recent research suggests that off-the-shelf video games may be a useful alternative. Studies of young adults have shown that video-game 'players' outperform 'non-players' (defined as persons who had not played any action video games within the prior 6 months) in visual and spatial processing tasks, and are more flexible and efficient at distributing attention ${ }^{16}$. Moreover, young adults were able to improve performance on visual-attention tests after only ten hours of training with a first-person-shooter (FPS) video game ${ }^{16,17}$. Such games require the player to shoot 'enemies' while maneuvering through a virtual environment that is viewed through the eyes of the shooter. The video-game skills of quickly detecting, identifying and tracking targets in cluttered visual displays and the rapid switching of attention between targets are believed to be fundamental to the observed improvements in visual processing ${ }^{16,18}$.

Video-game-based training offers a number of compelling advantages, compared to more traditional training approaches such as the UFOV program. For example, the enjoyable and "addictive" nature of video gaming ${ }^{19}$ would be expected to promote compliance with the training program, and features intrinsic to video-game design (repetition, progression in difficulty, augmented feedback, provision of rewards) should help to ensure effective learning. In addition, video games are widely available and relatively inexpensive, and the fact that they can be self-administered in the home, rather than in a clinical setting, should lead to further cost savings. Whereas the development of a new game-like training program could be a very expensive undertaking, use of an existing commercially-available video game to train improved visual processing in older adults would take advantage of the huge marketdriven efforts that have been, and continue to be, devoted to video-game development ${ }^{20}$.

At present, older adults are far less likely to play video games in comparison to younger persons. For example, a survey conducted in 2007 found that $81 \%$ of 18 - to 29 -yearolds play video games, while only $23 \%$ of adults age 65 or older report doing so ${ }^{21}$. However, older adults who do play video games tend to be among the most active gamers $^{22}$. Furthermore, it appears likely that the numbers of older persons playing video games will increase dramatically over the coming years due to the computer-literacy of the aging 'baby-boom' generation, the 
burgeoning numbers of older adults who are learning computer skills, and the rapidly increasing tendency of video-game companies to target a traditionally non-gaming older adult population $^{22-24}$.

There are, however, potential concerns about the suitability of FPS video games for an older-adult population. The games used in the previous young-adult visual-processing studies ${ }^{16,17}$ have involved realistic combat scenarios, which could trigger undue stress, particularly in older adults who may have lived through a war or similar traumatic events ${ }^{25,26}$. The problem is likely to be exacerbated as technological advances in image quality and sound fidelity increase the player's sense of presence and immersion in the virtual world ${ }^{27}$. Although there has been some previous work examining the suitability of video games for older adults ${ }^{28}$, we are not aware of any such studies that have examined highly realistic FPS games utilizing recent advances in computer technology.

The primary objectives of the present study were to determine: (i) whether older adults would be willing to play realistic and violent FPS video games; and (ii) the degree to which they would or would not enjoy such games in comparison to less violent alternatives. This initial study focussed on three video games that were selected to represent the three types of games that are most likely to find application in the training of visual processing (realistic-FPS, cartoon-FPS, fixedshooter). The UFOV training program was also assessed. Participants initially viewed and rated these four alternatives and were then given an opportunity to try them out and rate various features. We hypothesized that the participants would be less willing to play the realistic-FPS game in comparison to the less violent alternatives.

\section{Methods \\ Subjects}

Sixteen older adults (ages 64-77; mean $=70$, $\mathrm{SD}=4.2$ ) participated in the study, after providing signed informed consent in accord- ance with ethics approval granted by the institutional review board. Although gender differences were not a focus of the study, an effort was made to balance the gender distribution (9 female, 7 male). All participants were independent community-dwellers with no substantive cognitive impairments (Mini-Mental-State-Examination scores: 2730 , mean=29) or uncorrected visual deficits (Snellen-chart acuity: 20/40 or better, wearing corrective lenses if applicable). Most of the participants were familiar with using a computer (14/16 reported using a home computer for tasks such as email and internet access); however, none had any substantive prior video-gaming experience (only four participants reported any such experience, and this was limited to a single instance of playing a video game with a grandchild). One of the subjects reported a strong dislike of video games (complaining that his grandchildren played them too much); none of the other participants reported either a strong like or dislike.

\section{Selected video games}

The study focussed on three specific video games, as well as the UFOV training program which was presented to subjects as if it were a video game (Figure 1). The games were selected to be representative of the types of games that are most likely to find application in the training of visual processing. A realistic-FPS game was included based on the previous evidence that such a game can improve visual processing speed in young adults ${ }^{16,17}$. Because of the potential war-related sensitivities of the older adults $^{25,26}$, we elected to use a game with a non-war (counter-terrorism) scenario (Time Crisis) as the representative realistic-FPS game. Rayman Raving Rabbid was included as a cartoon-like, non-violent FPS alternative to the realistic FPS (participants shoot rubber sink plungers at comical cartoon depictions of rabbits). Given the possibility that fixed-shooter games (shooter is controlled to move back and forth on the screen while shooting objects that approach from the periphery of the screen) may have similar ben- 


\section{A t t it ud es}

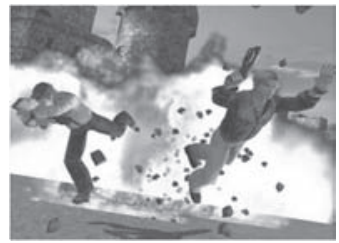

(A)

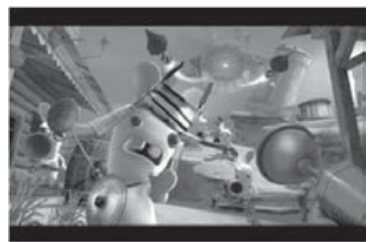

(B)

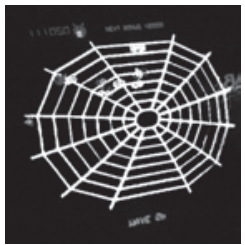

(C)

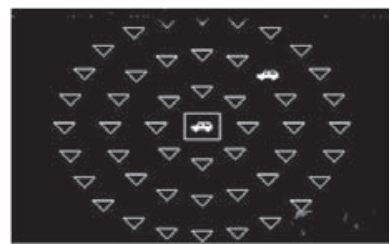

(D)

Figure 1. Example video images (screen captures) for the UFOV training program (D) and the three video games that were the focus of the study: A. realistic-FPS game (Time Crisis); B. cartoon-like FPS game (Rayman Raving Rabbid); C. fixed-shooter game (Black Widow)

efits, we also included an example of this genre (Black Widow). The UFOV program was included, in addition to the three video games, because the capacity of this program to improve visual processing in older adults has been well established ${ }^{13}$; however, to our knowledge, the level of enjoyment associated with this training program has not been evaluated previously.

\section{Protocol}

Each subject participated in an initial 30-minute observational session and four 30-minute experiential (game-playing) sessions, in isolation from the other subjects. These four sessions were spread out over three separate visits. During the initial visit, participants were first asked to observe short (30-60 s) video clips of the three video games indicated above, as well as the UFOV program. Video clips for a variety of other video games were included in this part of the protocol, in order to expose the subjects to a wide range of alternatives. For logistical reasons, it was necessary to present the video clips in the same (pseudo-random) order for all subjects; however, the UFOV program and three video games that were the focus of the study were all viewed near the mid-point or end of the session (Table 1).

Immediately following each video clip, subjects were asked to indicate via a structured questionnaire how they felt about the video clip and whether they would be willing to play the game that they had just observed. Participants who did not refuse to play were then asked to rate, on a 5-point Likert scale (very likely, somewhat likely, unsure, somewhat unlikely, very unlikely), the likelihood that they would want to play the game. All subjects were also asked to rate their likely

Table 1. Characteristics of the video clips viewed by all participants during the observational portion of the study, in the order of presentation; the three games and UFOV program that were the focus of the study are highlighted in italics

\begin{tabular}{c|lllc}
\hline$\#$ & Title (supplier web site) & Genre & \multicolumn{2}{l}{ Visual Display } \\
\hline 1 & Wii Fit Soccer ((www.nintendo.com) & Body interaction & 3D: Cartoon & 37 \\
2 & Link Crossbow Training (www.nintendo.com) & First person shooter & 3D: Cartoon & 48 \\
3 & Medal of Honor (www.us.playstation.com) & First person shooter & 3D: Realistic & 36 \\
4 & Eye Toy: Antigrav (www.us.playstation.com) & Body interaction & 2D: Cartoon & 38 \\
5 & Black Widow (www.atari.com) & Fixed shooter & 2D: Cartoon & 32 \\
6 & Millipede (www.atari.com) & Fixed shooter & 2D: Cartoon & 31 \\
7 & Dance Dance Revolution & Body interaction & 2D: Cartoon & 46 \\
& (www.us.playstation.com) & & \\
8 & Gran Turismo (www.us.playstation.com) & Driving simulator & 3D: Realistic & 30 \\
9 & Rayman Raving Rabbid (www.nintendo.com) & First person shooter & 3D: Cartoon & 53 \\
10 & Mario Kart (www.nintendo.com) & Driving simulator & 3D: Cartoon & 36 \\
11 & Time Crisis (www.us.playstation.com) & First person shooter & 3D: Realistic & 60 \\
12 & Useful Field of View (UFOV) & Training program & 2D: abstract & 60 \\
& (www.visualawareness.com) & & targets \\
\hline
\end{tabular}


level of enjoyment if they did play, using the same 5-point Likert scale.

The remainder of the initial visit, and the two subsequent visits, were devoted to trying out and rating the UFOV program and the three video games that were the focus of the study. Participants played for 30 minutes during each of the fixed-shooter and UFOV sessions, and played for 15 minutes with each of two types of controllers (Figure 2) during the realistic-FPS session and the cartoon-FPS session. A brief tutorial was given prior to starting each new game/ program and each change in controller. The order of game/program play was randomly determined for each participant, and the order of trying the two types of controllers was counterbalanced across participants. During each game-play session, participants stood or sat (according to their preference) approximately $1.7 \mathrm{~m}$ from a 27 -inch $(0.69 \mathrm{~m})$ television screen.

At the conclusion of each game-play session, participants were asked to complete a custom-designed questionnaire that as- sessed, on a five-point Likert scale (strongly agree, agree, unsure, disagree, strongly disagree), the degree to which they agreed or disagreed with the following statements: (i) 'I enjoyed playing the game', (ii) 'I would be willing to play the game again'; (ii) 'I was bothered by the theme of the game'; (iv) 'I found the game to be interesting'; (v) 'I found the game to be challenging'; (vi) 'I found the game to be frustrating'; or (vii) 'I felt anxious while playing the game'. Subjects who indicated that they would be willing to play the game again were also asked to estimate how many times per week they would be willing to play.

The same Likert scale was used to probe the participants' agreement or disagreement with statements about specific aspects of the visual display ('I found the display: too violent; too childish; moved too fast; confusing') and the audio track ('I liked the audio', 'I found the audio disturbing', 'I would prefer to play without audio'). Finally, subjects were probed about specific aspects of the different types of game controllers, via the following questions: "Which controller

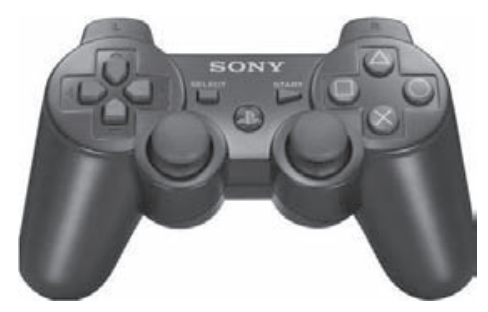

(A)

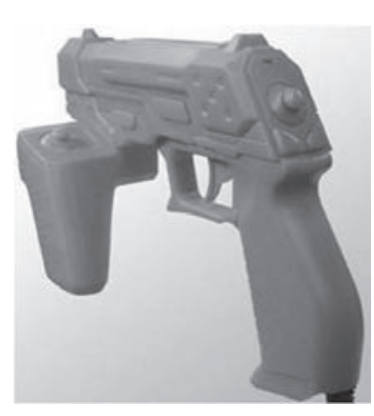

(B)

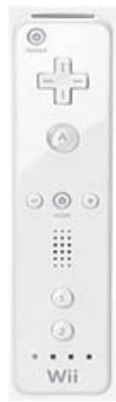

(C)

Figure 2. Photographs showing the standard and alternative controllers that were used during the gameplay sessions, for the realistic-FPS game (Time Crisis) and the cartoon-FPS game (Rayman Raving Rabbid): A. standard controller (used for both games);

B. gun-like point-and-shoot controller (the alternative controller for Time Crisis);

C. non-gun-like point-and-shoot controller (the alternative controller for Rayman Raving Rabbid).

With the standard controller, the subject manipulated a joystick with the left hand so as to move a cursor to the intended target on the screen, and then shot at the target by pushing a button with the right thumb. The alternative controllers required only one hand, and allowed enemies to be shot by pointing the device at the screen (thereby moving the cursor to the intended target) and pulling a trigger with the index finger. Only the standard controller was used during the fixed-shooter game, whereas the UFOV program simply required subjects to use a computer mouse to identify targets and target locations (with no temporal constraints) 
was easier to use?"; "Which controller gave the best control over movements on the screen?"; "Which controller felt more natural?"; "Given an option, which controller would you use?".

To avoid the possibility of biasing their ratings and responses, participants were not given any information about the potential beneficial effects of the UFOV program, video games in general or any specific games, at any point prior to the completion of the study.

\section{Statistical analysis and data presentation}

A statistical analysis was performed to test the hypothesis that participants would be less willing to play the realistic-FPS game, in comparison to the cartoon-FPS game, the fixed-shooter game and the UFOV program. The statistical model was a generalized linear mixed model, with a binary distribution for the dependent variable and with subjects treated as a random effect. The analyses were performed using SAS statistical software (version 9; PROC GLIMMIX).

Responses to other questions about various features of the games were summarized for descriptive and exploratory purposes, but were not subjected to statistical analysis. To simplify presentation of these data, the 5-point Likert data were pooled into three categories. Depending on the wording of the question, these three categories were either: (i) 'somewhat or very likely', 'unsure', 'somewhat or very unlikely'; or (ii) 'disagree or strongly disagree', 'unsure', 'agree or strongly agree'.

\section{Results}

\section{Video-clip demonstration}

The results of the observational session are consistent with the hypothesis that older adults would be less willing to play the realistic-FPS video games, in comparison to the other games viewed (Table 2). Viewing the video clip of the realistic-FPS game (Time Crisis) prompted a large percentage of the participants $(63 \%, 10 / 16)$ to indicate they would refuse to play the game if asked. In contrast, refusal rates for the UFOV program, cartoon-FPS game (Rayman Raving Rabbid) and fixed-shooter game (Black Widow) ranged from $0-25 \%(0 / 16$ to $4 / 16)$. Statistical analysis indicated a significant effect due to 'game' $[F(3,45)=5.06 ; p=0.0042]$, and post hoc least-squares comparisons of the model-parameter estimates indicated a significantly reduced willingness to play the realistic-FPS game in comparison to the cartoon-FPS game $(p=0.021)$, the fixed-shooter game $(p=0.0032)$ and the UFOV program $(p=0.0032)$. There were no significant differences between the latter three options $\left(p^{\prime} s>0.11\right)$.

Consistent with the unwillingness to play the realistic-FPS game, a very high percentage

Table 2. Willingness to play and anticipated level of enjoyment of all participants after viewing the video game demonstrations ( $N=16)$; FPS=First person shooter

\begin{tabular}{l|lcccc}
\hline \multirow{2}{*}{ Statement } & Opinion & \multicolumn{3}{c}{ Games and \% ratings (n) } \\
\cline { 2 - 5 } & & $\begin{array}{c}\text { Realistic } \\
\text { FPS }\end{array}$ & $\begin{array}{c}\text { Cartoon } \\
\text { FPS }\end{array}$ & $\begin{array}{c}\text { Fixed } \\
\text { shooter }\end{array}$ & UFOV \\
\hline $\begin{array}{l}\text { Likelihood of } \\
\text { playing if asked }\end{array}$ & Refused & $63(10)$ & $25(4)$ & $6(1)$ & $0(0)$ \\
& Very / somewhat unlikely & $13(2)$ & $6(11)$ & $13(2)$ & $19(3)$ \\
& Unsure & $0(0)$ & $0(0)$ & $13(2)$ & $6(1)$ \\
Anticipated level & Very / somewhat likely & $25(4)$ & $69(11)$ & $69(11)$ & $75(12)$ \\
of enjoyment & Very / somewhat unlikely & $88(14)$ & $25(4)$ & $50(8)$ & $25(4)$ \\
& Unsure & $0(0)$ & $19(3)$ & $25(4)$ & $25(4)$ \\
& Very / somewhat likely & $13(2)$ & $56(9)$ & $25(4)$ & $50(8)$ \\
\hline
\end{tabular}


Table 3. Overall comments after playing, only persons that tried the game are included; FPS=First person shooter

\begin{tabular}{|c|c|c|c|c|c|}
\hline \multirow[b]{2}{*}{ Statement } & \multirow[b]{2}{*}{ Opinion } & \multicolumn{4}{|c|}{ Games and \% ratings $(n)$} \\
\hline & & $\begin{array}{c}\text { Realistic FPS } \\
(n=6)\end{array}$ & $\begin{array}{c}\text { Cartoon FPS } \\
(n=12)\end{array}$ & $\begin{array}{l}\text { Fixed shooter } \\
\qquad(n=15)\end{array}$ & $\begin{array}{l}\text { UFOV } \\
(n=16)\end{array}$ \\
\hline \multirow[t]{3}{*}{ I would play again } & (Strongly) agree & $50(3)$ & $100(12)$ & $87(13)$ & $94(15)$ \\
\hline & Unsure & $0(0)$ & $0(0)$ & $7(1)$ & $6(1)$ \\
\hline & (Strongly) disagree & $50(3)$ & $0(0)$ & $7(1)$ & $0(0)$ \\
\hline \multirow{3}{*}{$\begin{array}{l}\text { I would be willing to } \\
\text { play }\end{array}$} & Daily & $33(2)$ & $33(4)$ & $13(2)$ & $6(1)$ \\
\hline & 1-3x /week & $17(1)$ & $67(8)$ & $60(9)$ & $88(14)$ \\
\hline & Never or Unsure & $50(3)$ & $0(0)$ & $27(4)$ & $6(1)$ \\
\hline
\end{tabular}

of participants $(88 \%, 14 / 16)$ anticipated that they would be 'somewhat' or 'very' unlikely to enjoy playing this game. In contrast, only 25 to $50 \%(4 / 16$ to $8 / 16)$ of the participants anticipated that they would be 'somewhat' or 'very' unlikely to enjoy playing the other three options. The graphic depiction of violence (particularly, gun violence directed at humans) was cited by nine of ten subjects as the reason for refusing to play the realisticFPS games. The one subject who had reported a strong dislike of video games (prior to the start of the observational session) refused to try any of the video games, but did agree to try out the UFOV program.

\section{Experiential game-play}

If a subject indicated an unwillingness to play a specific game (or the UFOV program) during the observational session, then s/he was not asked to try out that game during the experiential part of the protocol. As a consequence, only six subjects tried out the realistic-FPS game, 12 tried out the cartoonFPS game and 15 tried out the fixed-shooter game. All 16 subjects tried out the UFOV program. The number of subjects who tried out all four options was six. Six other subjects tried out only three options, three subjects tried out only two options, and one subject tried out only a single option.

\section{Willingness to play again}

The evidence from the observational session supporting the hypothesis that subjects would be less willing to play the realistic-FPS game is strengthened when one considers the results of the experiential session (Table 3). Of the six participants who were willing to try out the realistic-FPS game, only three indicated that they would be willing to play the game again, after trying it out. Since the other 10 participants were unwilling to even try out this game, one can infer that a total of 13 subjects would be unwilling to play the realistic-FPS game in the future. The corresponding totals for the UFOV, fixed-shooter and cartoon-FPS were only one, two and four subjects, respectively. Statistical analysis of these totals confirmed a significant effect due to 'game' $[F(3,45)=6.47 ; p=0.0010]$ and a significantly-reduced willingness to play the realistic-FPS game in comparison to the other three options $\left(p^{\prime} s<0.0023\right)$.

\section{Emotional responses}

Only three of the six participants who were willing to try out the realistic-FPS game reported that they enjoyed playing the game (Table 4). In contrast, all 12 of the participants who agreed to try out the cartoon-FPS game reported that they enjoyed playing it, and enjoyment was also reported by the vast majority of the participants who were willing to try out the UFOV program (15/16) and the fixed-shooter game (14/15).

All subjects who tried out the video games found them to be challenging, and all but one were challenged by the UFOV program. Most found the sessions interesting (4/6 for the realistic-FPS game, 10/12 for the car- 


\section{A thitudes toward video games}

Table 4. Emotional factors in gaming and their rating for the four games and UFOV training; only persons who tried the game are included; FPS=First person shooter

\begin{tabular}{|c|c|c|c|c|c|}
\hline \multirow[b]{2}{*}{ Statement } & \multirow[b]{2}{*}{ Opinion } & \multicolumn{4}{|c|}{ Games and \% ratings $(n)$} \\
\hline & & $\begin{array}{c}\text { Realistic FPS } \\
(n=6)\end{array}$ & $\begin{array}{l}\text { Cartoon FPS } \\
\qquad(n=12)\end{array}$ & $\begin{array}{l}\text { Fixed shooter } \\
\qquad(n=15)\end{array}$ & $\begin{array}{l}\text { UFOV } \\
(n=16)\end{array}$ \\
\hline \multirow{3}{*}{$\begin{array}{l}\text { The theme of this } \\
\text { game bothered me }\end{array}$} & (Strongly) agree & $17(1)$ & $0(0)$ & $0(0)$ & $6(1)$ \\
\hline & Unsure & $17(1)$ & $8(1)$ & $27(4)$ & $0(0)$ \\
\hline & (Strongly) disagree & $67(4)$ & $92(11)$ & $73(11)$ & $94(15)$ \\
\hline \multirow[t]{3}{*}{ I enjoyed the game } & (Strongly) agree & $50(3)$ & $100(12)$ & $80(12)$ & $94(15)$ \\
\hline & Unsure & $33(2)$ & $0(0)$ & $20(3)$ & $6(1)$ \\
\hline & (Strongly) disagree & $17(1)$ & $0(0)$ & $0(0)$ & $0(0)$ \\
\hline \multirow{3}{*}{$\begin{array}{l}\text { I found the game } \\
\text { interesting }\end{array}$} & (Strongly) agree & $67(4)$ & $83(10)$ & $80(12)$ & $81(13)$ \\
\hline & Unsure & $17(1)$ & $17(2)$ & $20(3)$ & $19(3)$ \\
\hline & (Strongly) disagree & $17(1)$ & $0(0)$ & $0(0)$ & $0(0)$ \\
\hline \multirow{3}{*}{$\begin{array}{l}\text { I found the game } \\
\text { challenging }\end{array}$} & (Strongly) agree & $100(6)$ & $100(12)$ & $100(15)$ & $94(15)$ \\
\hline & Unsure & $0(0)$ & $0(0)$ & $0(0)$ & $6(1)$ \\
\hline & (Strongly) disagree & $0(0)$ & $0(0)$ & $0(0)$ & $0(0)$ \\
\hline \multirow{3}{*}{$\begin{array}{l}\text { I found the game } \\
\text { frustrating }\end{array}$} & (Strongly) agree & $50(3)$ & $0(0)$ & $33(5)$ & $6(1)$ \\
\hline & Unsure & $17(1)$ & $17(2)$ & $20(3)$ & $31(5)$ \\
\hline & (Strongly) disagree & $33(2)$ & $83(10)$ & $47(7)$ & $63(10)$ \\
\hline \multirow{3}{*}{$\begin{array}{l}\text { I felt anxious while } \\
\text { playing the game }\end{array}$} & (Strongly) agree & $50(3)$ & $42(5)$ & $47(7)$ & $13(2)$ \\
\hline & Unsure & $0(0)$ & $17(2)$ & $6(1)$ & $13(2)$ \\
\hline & (Strongly) disagree & $50(3)$ & $42(5)$ & $47(7)$ & $75(12)$ \\
\hline
\end{tabular}

toon-FPS game, 12/15 for the fixed-shooter game, and 13/16 for the UFOV program). Approximately half of the participants found playing the three video games to be anxietyprovoking, but only $12 \%(2 / 16)$ reported that they felt anxious when trying out the UFOV program. Frustration was quite common when playing the realistic-FPS and fixedshooter games [50\% (3/6) and 33\% (5/15) of participants, respectively], but this was not the case for the cartoon-FPS game $(0 \%$, $0 / 12)$ or the UFOV program $(6 \%, 1 / 16)$.

\section{Visual displays}

None of the participants found the cartoonFPS, fixed-shooter or UFOV video display to be 'too violent' (Table 5). In contrast, the violent nature of the realistic-FPS display was a concern for the majority $(69 \%, 11 / 16)$ of participants (ten refused to play this game due to the high level of violence, and one of the six who was willing to play reported being troubled by the violence after trying it out). Potential concerns that subjects might perceive the cartoon-FPS video display as being 'too childish' were not strongly supported by the data, as this was the case in only $8 \%$ of participants (1/12). Few subjects (0 to 2) found any of the visual displays to be 'confusing'; however, a sizeable proportion felt that the visual display 'moved too fast' in the realistic-FPS game $(33 \%, 2 / 6)$, fixedshooter game $(47 \%, 7 / 15)$ and UFOV program $(44 \%, 7 / 16)$. Only $8 \%$ of subjects $(1 / 12)$ were bothered by the speed of the display in the cartoon-FPS game.

\section{Audio track}

The audio track that accompanied the cartoon-FPS game was enjoyed by $75 \%$ (9) of the 12 participants who played this game (Table 6). Ratings were somewhat lower for the other two video games (there was no audio track for the UFOV program). Of the six 
Table 5. Visual display of games and UFOV training and their rating for the four games and UFOV training; only persons that tried a game are included; FPS=First person shooter

\begin{tabular}{|c|c|c|c|c|c|}
\hline \multirow[b]{2}{*}{ Statement } & \multirow[b]{2}{*}{ Opinion } & \multicolumn{4}{|c|}{ Games and $\%$ ratings $(n)$} \\
\hline & & $\begin{array}{c}\text { Realistic FPS } \\
(n=6)\end{array}$ & $\begin{array}{l}\text { Cartoon FPS } \\
\quad(n=12)\end{array}$ & $\begin{array}{l}\text { Fixed shooter } \\
\quad(n=15)\end{array}$ & $\begin{array}{l}\text { UFOV } \\
(n=16)\end{array}$ \\
\hline \multirow{3}{*}{$\begin{array}{l}\text { I found the game too } \\
\text { violent }\end{array}$} & (Strongly) agree & $17(1)$ & $0(0)$ & $0(0)$ & $0(0)$ \\
\hline & Unsure & $17(1)$ & $8(1)$ & $13(2)$ & $0(0)$ \\
\hline & (Strongly) disagree & $67(4)$ & $92(11)$ & $87(13)$ & $100(16)$ \\
\hline \multirow{3}{*}{$\begin{array}{l}\text { I found that the } \\
\text { visual information } \\
\text { moved too fast }\end{array}$} & (Strongly) agree & $33(2)$ & $8(1)$ & $47(7)$ & $44(7)$ \\
\hline & Unsure & $17(1)$ & $17(2)$ & $6(1)$ & $19(3)$ \\
\hline & (Strongly) disagree & $50(3)$ & $75(9)$ & $47(7)$ & $38(6)$ \\
\hline \multirow{3}{*}{$\begin{array}{l}\text { I found the visual } \\
\text { display confusing }\end{array}$} & (Strongly) agree & $17(1)$ & $0(0)$ & $13(2)$ & $6(1)$ \\
\hline & Unsure & $33(2)$ & $25(3)$ & $13(2)$ & $13(2)$ \\
\hline & (Strongly) disagree & $50(3)$ & $75(9)$ & $73(11)$ & $81(13)$ \\
\hline \multirow{3}{*}{$\begin{array}{l}\text { I found the visual } \\
\text { display too childish }\end{array}$} & (Strongly) agree & $17(1)$ & $8(1)$ & $7(1)$ & $0(0)$ \\
\hline & Unsure & $17(1)$ & $8(1)$ & $20(3)$ & $0(0)$ \\
\hline & (Strongly) disagree & $67(4)$ & $83(10)$ & $73(11)$ & $100(16)$ \\
\hline
\end{tabular}

subjects who played the realistic-FPS game, half reported that they enjoyed the audio (gunfire, shouting and music), whereas the other three subjects were unsure. The audio track for the fixed-shooter game (missile fire and explosions) was enjoyed by $53 \%$ (8) of the 14 subjects who rated this game, although some described it as 'grating and irritating'. Despite the concerns raised by some participants related to the audio, most agreed that they would prefer to play the video games with the audio turned on as it helped provide a context for the game (for instance, successful action, impending danger).

\section{Controllers and physical discomfort}

Within the participants who played the FPS games, there was nearly unanimous consensus that the point-and-shoot controller was easier to use than the standard controller (joystick and push buttons). All of

Table 6. Audio track of games training and their rating for the four games and UFOV training; UFOV is not included since it has no audio track; only persons that tried a game are included; FPS=First person shooter

\begin{tabular}{|c|c|c|c|c|}
\hline \multirow[b]{2}{*}{ Statement } & \multirow[b]{2}{*}{ Opinion } & \multicolumn{3}{|c|}{ Games and \% ratings $(n)$} \\
\hline & & $\begin{array}{c}\text { Realistic FPS } \\
\qquad(\mathrm{n}=6)\end{array}$ & $\begin{array}{l}\text { Cartoon FPS } \\
(n=12)\end{array}$ & $\begin{array}{l}\text { Fixed shooter } \\
\qquad(\mathrm{n}=14)\end{array}$ \\
\hline \multirow{3}{*}{$\begin{array}{l}\text { I liked the audio for this } \\
\text { game }\end{array}$} & (Strongly) agree & $50(3)$ & $75(9)$ & $57(8)$ \\
\hline & Unsure & $50(3)$ & $17(2)$ & $29(4)$ \\
\hline & (Strongly) disagree & $0(0)$ & $8(1)$ & $14(2)$ \\
\hline \multirow[t]{3}{*}{ I found the audio disturbing } & (Strongly) agree & $17(1)$ & $0(0)$ & $7(1)$ \\
\hline & Unsure & $0(0)$ & $8(1)$ & $14(2)$ \\
\hline & (Strongly) disagree & $83(5)$ & $92(11)$ & $79(11)$ \\
\hline \multirow{3}{*}{$\begin{array}{l}\text { I would prefer to play the } \\
\text { game without audio }\end{array}$} & (Strongly) agree & $33(2)$ & $8(1)$ & $0(0)$ \\
\hline & Unsure & $17(1)$ & $17(2)$ & $29(4)$ \\
\hline & (Strongly) disagree & $50(3)$ & $75(9)$ & $71(10)$ \\
\hline
\end{tabular}


the six realistic-FPS players and 11 of the 12 cartoon-FPS players reported that the pointand-shoot controller provided the best control of the cursor movement on the screen and would be their preference when playing again. None of the subjects reported any physical discomfort following any of the game-play sessions.

\section{Discussion}

\section{Enjoyment and willingness to play}

Our specific interest, in performing this initial study, was to identify a video game that could be used as the foundation for a program to train more rapid and effective visual processing in older adults. By providing our participants with the opportunity to observe video-clip demonstrations of different genres of video games, we were able to identify their willingness to try out different types of games during the subsequent game-play sessions, while remaining respectful of potential sensitivities to graphic depictions of violence. Although previous work has demonstrated that young adults are willing to engage in video-game training sessions that depict realistic and graphic violence ${ }^{16,17}$, the present results clearly support our hypothesis that the majority of older adults would be opposed to playing such games. In particular, participants expressed their distaste for the graphic visual displays (for instance, people being shot, blood covering the screen), as well as the associated audio track (for instance, gunfire, people shouting), and the gun-like appearance of the controller likely contributed to the negative reactions.

Even though the majority of the older adults were not interested in playing the realisticFPS video game, almost all were amenable to trying out the cartoon-FPS and fixedshooter games, and all were willing to try the UFOV program. All participants had some familiarity with video games and most relayed stories of watching their own children or grandchildren play; however, only four participants described an occasion of actually playing a video game themselves. Despite the lack of prior experience and a general indifference toward video games expressed prior to the study, most of the participants embraced the game-play sessions and reported positive feelings of challenge and enjoyment and a willingness to play again (a notable exception being the one subject who expressed a strong dislike of video games prior to starting the study). Somewhat surprisingly, reported levels of frustration in trying out each game/program for the first time were quite low (particularly for the cartoon-FPS and UFOV), despite the fact that virtually all the subjects found the video games and UFOV program to be challenging.

\section{Specific features of the video games}

A previous review ${ }^{28}$ concluded that video games that involve small objects, require rapid reactions, include inappropriate sound effects, or provoke frustration or disinterest are unsuitable for older adults. In the present study, the playing of the realistic-FPS and fixed-shooter games, as well as the UFOV program, did elicit some complaints that are consistent with some of these conclusions. Examples of such complaints include: 'moved too quickly' $(n=7)$, 'sound track was alarming' ( $\mathrm{n}=2)$, 'too many colors' $(\mathrm{n}=1)$ and 'too confusing' ( $\mathrm{n}=2)$. Associated with these complaints were comments such as: 'the game was not fun' ( $n=2)$ and 'I wouldn't want to play it for more than 10 minutes' $^{\prime}$ $(n=1)$. In contrast, the cartoon-FPS game was nearly-unanimously identified as being enjoyable, interesting and challenging and associated with low levels of frustration, and was regarded as being 'too childish' by only one subject. Associated comments included: 'very challenging and fun' $(n=5)$; 'I like the characters and the costumes' $(n=4)$; and 'I could spend a lot of time shooting those little guys' $(n=1)$.

As suggested by previously-observed relationships between cognitive abilities and technology adoption ${ }^{29}$, it is also important to ensure that the game interface is easy for seniors to use and provides cues that reduce undue demands on working memory ${ }^{30}$. The 
point-and-shoot controllers evaluated in the present study were designed to provide intuitive control over actions on the screen, thereby avoiding the need to remember keystrokes, and our subjects did indeed prefer to use this type of controller. Note, however, that the ease of using the controllers was not a major determinant of willingness to play, in this study. The decisions whether to try out the games were made prior to any exposure to the controllers, and no subjects reported that ease of controller use affected how they rated their desire to play the game again (after the try-outs).

\section{Limitations and the need for further research}

The sample of 16 subjects used in this initial study was sufficient to test our hypothesis that older adults would be less willing to play the realistic-FPS video games, in comparison to the less violent games. The study also provided some descriptive information about the participants' perceptions regarding specific aspects of the tested games. Clearly, however, further research with larger samples is needed to: (i) investigate the specific features of video games that influence enjoyment and willingness to play; (ii) determine which features of the games optimize benefits (such as improvements in visual processing); (iii) correlate objective measures of game performance with attitudes toward the games as well as benefits derived from playing the games; and (iv) examine these issues in cohorts encompassing a wide range of educational backgrounds, technical skills and computer expertise. A valuable methodological lesson to be learned from the initial work performed here is the need, in future, to account for the reluctance of many older adults to play certain types of video games when estimating required sample sizes.

It will also be important, in future studies, to provide participants with greater opportunity to try out the games, beyond the

\section{Acknowledgements}

This study was funded by grants from the Canadian Institutes of Health Research (grants \#MOP-13355 and \#MAT-91865) and the Ontario 30-minute exposure that was provided in the present study, and to determine whether the willingness to play persists on an ongoing basis. It is possible that persons' impressions of the games will change if they are given greater exposure to the games, or if they are given motivational information (for instance, informing them that playing the games may have health-related benefits). Previous findings suggest that factors such as the inclusion of an engaging story line and the degree to which the game involves arousing or 'addictive' stimuli ${ }^{31}$ may also warrant further study as factors that may influence both enjoyment and learning of improved visual processing skills.

\section{Conclusion}

In conclusion, the results of this study clearly indicate that a realistic and violent FPS video game is not likely to be an appropriate choice for many older adults. A non-realistic, nonviolent cartoon-FPS video game may well be just as effective in improving visual processing, and is much more likely to be tolerated and enjoyed by seniors. The non-realistic fixedshooter game was also well tolerated and has the potential to improve visual processing; however, visual-processing benefits of playing this type of game have not yet been established. Although most of the present subjects also enjoyed the UFOV training program, a video-game training program could offer important advantages related to the relatively low cost and widespread availability of video games, the 'addictive' and arousing properties of these games and the potential for self-administered training at home. We therefore conclude that non-violent cartoonFPS and fixed-shooter video games warrant further investigation as an alternative to the UFOV program for training improved visual processing in seniors. One such study, with the underlying objective of improving reachto-grasp balance-recovery reactions, is currently in progress ${ }^{32}$.

Neurotrauma Foundation (grant \#ONF2007PREV-INT-547). The authors thank Ravi Bhanabhai, Aaron Marquis, Kenneth Cheng, Emily King and Rachel Keshwah for their assistance. 
The authors also thank and acknowledge Dr. Ellen Maki for providing statistical advice.

\section{References}

1. Ball K, Owsley C, Beard B. Clinical visual perimetry underestimates peripheral field problems in older adults. Clinical Vision Sciences 1990;5(2):113-125

2. Sekuler AB, Bennett PJ. Effects of aging on the useful field of view. Experimental Aging Research 2000;26(2):103-120; doi:10.1080/036107300243588

3. Broman AT, West SK, Munoz B, BandeenRoche K, Rubin GS, Turano KA. Divided visual attention as a predictor of bumping while walking: The Salisbury eye evaluation. Investigative Ophthalmology \& Visual Science 2004;45(9):2955-2960; doi:10.1167/ iovs.04-0219

4. Owsley C, McGwin G. Association between visual attention and mobility in older adults. Journal of the American Geriatrics Society 2004;52(11):1901-1906; doi:10.1111/j.1532-5415.2004.52516.x

5. Ball K, Owsley C, Sloane ME, Roenker DL, Bruni JR. Visual-attention problems as a predictor of vehicle crashes in older drivers. Investigative Ophthalmology \& Visual Science 1993;34(11):3110-3123; doi:10.1167/ iovs.04-0219

6. Owsley C, Ball K, McGwin G Jr, Sloane ME, Roenker DL, White MF, Overley ET. Visual processing impairment and risk of motor vehicle crash among older adults. Journal of the American Medical Association 1998;279(14):1083-1088; doi:10.1001/ jama.279.14.1083

7. Maki BE, Mcllroy WE. Effects of aging on control of stability. In: Luxon L, Martini A, Furman J, Stephens D, editors. A Textbook of Audiological Medicine: Clinical Aspects of Hearing and Balance. London: Martin Dunitz; 2003; pp 671-690

8. Maki BE, Mcllroy WE. Change-in-support balance reactions in older persons: an emerging research area of clinical importance. Neurologic Clinics 2005;23(3):751783; doi:10.1016/j.ncl.2005.01.002

9. King EC, McKay SM, Lee TA, Scovil CY, Peters AL, Maki, BE. Gaze behavior of older adults in responding to unexpected loss of balance while walking in an unfamiliar environment: a pilot study. Journal of Optometry 2009;2(3):119-126; doi:10.3921/ joptom.2009.119

10. Maki BE, Mcllroy WE. Cognitive demands and cortical control of human balancerecovery reactions. Journal of Neural Transmission 2007;114(10):1279-1296; doi:10.1007/s00702-007-0764-y

11. Ball K, Sekuler R. Improving visual percep- tion in older observers. Journal of Gerontology 1986;41(2):176-182

12. Ball KK, Beard BL, Roenker DL, Miller RL, Griggs DS. Age and visual-search - expanding the useful field of view. Journal of the Optical Society of America (A-Optics, Image Science and Vision) 1988;5(12):22102219; doi:10.1364/JOSAA.5.002210

13. Ball K, Owsley C. Increasing mobility and reducing accidents of older drivers. In: Warner Schaie K, Pietrucha M, editors. Mobility and Transportation in the Elderly. New York: Springer; 2000, pp 213-250

14. Roenker DL, Cissell GM, Ball KK, Wadley VG, Edwards JD. Speed of processing and driving simulator training result in improved driving performance. Human Factors 2003;45(2):218-233; doi:10.1518/ hfes.45.2.218.27241

15. Edwards JD, Wadley VG, Myers RS, Roenker DL, Cissell GM, Ball KK. Transfer of a speed of processing intervention to near and far cognitive functions. Gerontology 2002;48(5):329-40; doi:10.1159/000065259

16. Green CS, Bavelier D. Action video game modifies visual selective attention. Nature 2003;423(4):534-537; doi:10.1038/nature01647

17. Feng J, Spence I, Pratt J. Playing an action video game reduces gender differences in spatial cognition. Psychological Science 2007;18(10):850-855; doi:10.1111/j.14679280.2007.01990.x

18. Riesenhuber M. An action video game modifies visual processing. Trends in Neurosciences 2004;27(2):72-74; doi:10.1016/j. tins.2003.11.004

19. Gentile D, Gentile J. Violent video games as exemplary teachers: A conceptual analysis. Journal of Youth and Adolescence 2008;37(2):127-141; doi:10.1007/s10964007-9206-2

20. Baranowski T, Buday R, Thompson DI, Baranowski J. Playing for real: Video games and stories for health-related behavior change. American Journal of Preventative Medicine 2008;34(1):74-82; doi:10.1016/j. amepre.2007.09.027

21. Pew Internet and American Life Project Reports; www.pewinternet.org; retrieved December 15, 2009

22. Charness N, Boot WR. Aging and information technology use: potential barriers. Current Directions in Psychological Science 2009;18(5):253-258; doi:10.1111/j.14678721.2009.01647.x

23. Beisgen B, Kraitchman M. Lifelong learning. Senior Centers: Opportunities for Successful Aging. New York; 2003; pp 69-90

24. McConatha D. Aging online: Toward a theory of e-quality. In: Morrell RW, editor. 
Older Adults, Health Information, and the World Wide Web. New Jersey: Lawrence Erlbaum; 2002; pp 21-41

25. Buffum MD, Wolfe NS. Posttraumatic stress disorder and the World War II veteran. Geriatric Nursing 1995;16(6):264-270; doi:10.1016/S0197-4572(95)80006-9

26. Elliott DM. Traumatic events: Prevalence and delayed recall in the general population. Journal of Consulting and Clinical Psychology 1997;65(5):811-820; doi:10.1037/0022-006X.65.5.811

27. Schneider EF, Lang A, Shin MB. Death with a story: How story impacts emotional, motivational, and physiological responses to first-person shooter video games. Human Communication Research 2004;30(3):361375; doi:10.1093/hcr/30.3.361

28. Whitcomb GR. Computer games for the elderly. In: Symposium on Computers and the Quality of Life: Proceedings of the conference on computers and the quality of life; 1990, September 13-16; George Washington University; Washington; pp 112-115

29. Czaja SJ, Charness N, Fisk AD, Hertzog C, Nair SN, Rogers WA, Sharit J. Factors predicting the use of technology: Findings from the Center for Research and Education on Aging and Technology Enhancement (CREATE). Psychology and Aging 2006;21(2):333-352; doi:10.1037/08827974.21.2.333

30. Fisk AD, Rogers WA, Charness N, Czaja SJ, Sharit J. Designing for Older Adults: Principles and Creative Human Factors Approaches. Boca Raton: CRC Press; 2004; pp 158

31. Koepp MJ, Gunn RN, Lawrence AD, Cunningham VJ, Dagher A, Jones T, Brooks DJ, Bench CJ, Grasby PM. Evidence for striatal dopamine release during a video game. Nature 1998;393(6682):266-288; doi:10.1038/30498

32. McKay SM, King EC, Cheng KC, Maki BE. Visual processing and balance reactions: development and pilot testing of a "visual training" program to improve change-insupport reactions in older adults. In: Chiari L, Nardone A, editors. Proceedings of the XIX Conference of the International Society for Posture and Gait Research. Bologna: University of Bologna; 2009; pp 339 